\title{
Linkages between Inflation and Economic Growth in Serbia: an ARDL Bounds Testing Approach
}

\author{
Sasa Obradovic, Srdan Sapic, Srđan Furtula, Nemanja Lojanica \\ University of Kragujevac \\ Djure Pucara 3, 34000 Kragujevac, Serbia \\ E-mail.sobradovic@kg.ac.rs, ssapic@kg.ac.rs,furtulas@kg.ac.rs,nlojanica@kg.ac.rs \\ cross $^{\text {ref }}$ http://dx.doi.org/10.5755/j01.ee.28.4.14003
}

\begin{abstract}
In the context of measuring the effects of structural policy, the analysis of the relation of economic growth and inflation is essential for the economy of the Republic of Serbia. The high inflation rate for years has caused macroeconomic instability in the Serbian economy. We examine the effects of inflation on growth in the case of Serbia. Consequently, the main objective of this study is to examine the link between inflation and economic growth. As an appropriate methodological framework for establishing the long run relationship (cointegration) between variables, we used ARDL model, while TodaYamamoto procedure was used for testing the short run causality. The period of observation was from Q1 2007 to Q3 2014. The results showed the presence of the cointegration between variables in the long run, and that in the short run a unidirectional causality from inflation to economic growth was present. According to the result of the conducted empirical study, it can be noted that the price stability is essential for the sustainable growth, although economic growth has been linked to the moderate increase of inflation in the short run.
\end{abstract}

Keywords: Inflation, Economic Growth, ARDL Model, Toda-Yamamoto Causality Test, Serbian Economy.

\section{Introduction}

Inflation, economic growth and unemployment are the key macroeconomic variables that are always in the focus of public attention. The inflation rate and the unemployment rate create a general picture of the economic development. The data on the gross domestic product is generally used for measuring the economic growth, as it represents approximation of the living standard. The basis for the analysis of inflation and growth in Serbia is the results of the previous studies, which allow simulation and conduction of the empirical model and, thus, the indirect quantification of the influence of economic and structural reforms on economic growth.

The relationship between real GDP growth and inflation is very important to policymakers, who are responsible for taking appropriate measures and solutions in order to provide a sustainable increase in the living standard. Testing the relation between economic growth and inflation is one of the major macroeconomic issues. A long-debated question in macroeconomics is whether inflation systematically affects output and do policymakers face a menu from which combinations of output and inflation may be chosen (Simhon \& Bar-Shira, 2001). This type of analysis has never been done before in the case of Serbian economy and in this paper the given analysis will be conducted. The records on this issue do not exist in the scientific literature. Therefore, as in most macroeconomic issues, this one causes a lot of controversy.

In the course of the Keynesian economic policy, a higher inflation rate is, as a rule, linked with reduced unemployment rate, which, ultimately has to contribute to higher economic growth. According to Keynesian economics, inflation affects economic growth and it can have impact on un-equalized allocation of resources, particularly if it is rather high. On the other hand, Friedman (1983) has argued that inflation is, in the first place, a monetary phenomenon and it has no impact on real variables of an economy. In other words, the increase of money supply presumably leads to rising prices rather than to the increase of economic growth rate.

Taking into consideration the importance of this issue, this study aims to extend this line of research by focusing on testing the linkages between inflation and economic growth in the economy of the Republic of Serbia. The variable of unemployment is treated as a control variable in further modelling. With respect to the defined purpose, the basic hypothesis, the work starts with the following: Price stability ensures a long-term sustainable economic growth in the Republic of Serbia, although economic growth is connected with a modest inflation rate increase in the short run. Therefore, a long-term interest prevails over a short-term one.

This is particulary important considering that, historically, inflation has determined economic circumstances in the Republic of Serbia over a number of years. A high inflation rate has been one of the charasteristics of the Serbian economy. This situation is caused by a number of various reasons, from the weaknesses of the system of the economy to the high budget deficit, which at one point, led to hyperinflation during the 1990`s.

In the beginning of the new millenium the Republic of Serbia did not manage to reach single-digit inflation rate; it remained double-digit one. The reason for this may be the inflationary action of the growth of the domestic demand and total public expenditure. Figure 1 shows the movement 
of the economic growth and inflation in Serbia from 2007 to 2014. According to the data from the National Bank of Serbia it can be detected that inflation was the highest in $2012(12,7 \%)$. In general, the inflation in the Republic of Serbia in the observed period was very high. Even the global crisis, that is deflationary pressure caused by the reduction of the aggregate demand, did not notably affect the decrease of this rate. On the other hand, the economic growth is followed by significant fluctuation. The real GDP fall was as much as 3,5\% in 2009.

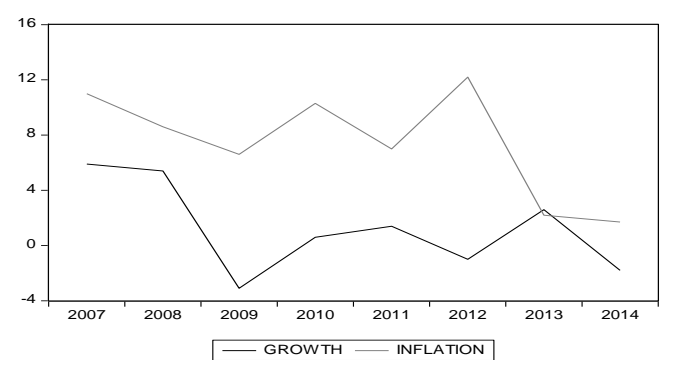

Figure 1. Inflation and Economic Growth in Serbia

The structure of the paper is as follows: the next section refers to the previous research on the relation of economic growth and inflation. Due to the importance of the relation between these variables, when designing a proper macroeconomic policy, the basic types of relations between these variables are described. The third part describes methodology and data, and shows the basic tests we used. The sections following this one present the results of the research including the conducted Toda-Yamamoto procedure. Finally, the concluding observations involve a discussion of the obtained results, which can be compared with the previous research.

\section{Literature Review}

This part of the paper presents the key characteristics of the selected empirical studies examining the causal relationship between inflation and economic growth. Literature review will not be limited only to European countries, but the focus will be on diversity of the results in terms of causality, regardless of the geographical area. Furthermore, there is a relation between the rate of inflation and the level of demand in the economy - time invariant relationship. This may not refer to the case in the long run, whereby, economic theory offers no guidance as to how long, the long run might be in practice (Ormerod et al., 2013). The investigation of the relation between economic growth, inflation and unemployment is a topic of numerous debates, however, without the agreement on a unified theoretical approach.

The significance of the analysis and mutual dynamic of these variables was first pointed out in a study by Phillips (1962). The effects of inflation on economic activity were presented through economic growth models. The uncertainty followed by high and volatile unanticipated inflation was regarded as a key factor that has negative effects on return on equity and investments and therefore on per capita income (Pindyck \& Solimano, 1993). In addition, inflation can cause a negative effect on macroeconomic stability through total factor productivity decrease. High inflation affects economic activity through growth in costs and the distortion of resource allocation efficiency. These theoretical approaches provide a support to the monetary policies carried out by the majority of central banks, and referring to price stability as a long-term goal of monetary policy (Barro, 1995; Andres \& Hernando, 1997). Fischer (1977) found out that monetary policy affects shortterm behavior of output but has no effect on long-term economic growth. Regarding various theoretical standpoints on relation between inflation and economic growth, the aim of our research is to analyze the issue from a very particular empirical angle.

At present, there is a solid theoretical and empirical reference observing the potential relationship between economic growth and inflation in both, developed and developing countries. It is interesting to point out that the Serbian economy was once struck by one of the largest ever recorded hyperinflation in the world history. Therefore, the question of the relationship of these indicators can greatly determine the economic situation in the economy of Serbia. The negative long-term relation between these two variables was established in some studies (Valdovinos, 2003; Caporale \& Skare, 2014). Balcilar et al. (2017) suggest that the linkages between economic growth and inflation is hump shaped. On the other hand, Mallik and Chowdury (2001) examined the long-term relationship between inflation and economic growth in the case of the four countries of South Asia: Bangladesh, India, Pakistan and Sri Lanka. Their results suggest that moderate inflation have a positive impact on economic growth, while faster economic growth absorbs the effects of inflation on "overheating" of the economy. Similar results were found in the study that has been done by Baharumshah et al. (2016). There are also studies which have not confirmed the long-term relations between the two variables (Faria \& Carneiro, 2001; Erbaykal \& Okuyan, 2008). The divergence of the results is the basic characteristic of the previous researches. Numerous causes can be stated as the reason: the specificity of the variable observation period, the specificity of the given national economy, as well as the implementation of a large number of different techniques applied in the empirical studies.

From the short run point, certain types of causality were differentiated. On the basis of the results of the previous studies, it is possible to distinguish several types of causal relations between inflation and economic growth. Each of these relations carries corresponding political implications. When the sign of causality is negative, the appropriate macroeconomic implication relates to the need of maintaining price stability for sustainable growth, while in the case of a positive sign, moderate inflation can be viewed as a link for improving the growth performance. Unidirectional causal relationship from economic growth to inflation, means that changes in economic growth lead to changes in the rate of inflation. The economic implications of such a result are related to the lack of impact of inflation on economic growth. According to Jayathileke and Rathnayake (2013), it is the characteristic of the countries with high rates of growth and a stable macroeconomic environment. The bidirectional causal relationship between inflation and economic growth, was established in the work (Koulakiotis et al., 2012). The above-mentioned authors have come to this finding using the panel sample of 14 European countries. 
The previous discussions show mixed results from different studies in literature. This study, in the next step, augments the literature in three ways: firstly, in addition to standard unit root tests, Zivot and Andrews trended structural breaks unit root test (1992) is used to test the order of integration of the variables considered. Secondly, ARDL model was applied to investigate the long run relationship between inflation and economic growth, which has never used before in the previous studies in the case of Serbia. Finally, Toda-Yamamoto Granger non-causality test is applied to detect the direction of the causality relationship between variables.

\section{Framework Modelling and Data}

In this part of the paper, we present the econometric methodology with empirical data. Economic growth is expressed as the Gross Domestic Product (in constant prices of the previous year), unemployment according to the Survey, and inflation through the Consumer Price Index. The research priority is the relation between economic growth and inflation rate. The third variable is of auxiliary character in modelling, and is used to reduce the problem of suspected causal effects due to non-inclusion of important variables in the analyzed relation. For all three variables that are the subject of this analysis, quarterly data are used and they cover the period from the first quarter of 2007 to the third quarter of 2014 (31 observations). The data on gross domestic product (in millions of dinars) and unemployment were taken from the website of the Republic Institute for Statistics, while the inflation data were taken from the website of the National Bank of Serbia (NBS). The data may serve as relevant once, although the conclusions should be taken with certain caution as they refer to the period of less than eight years (limited time window), with relatively unstable economic activity which was partly caused by the global economic recession.

In order to apply any of the testing methods of causality and interconnections in the first step, it is necessary to test the stationarity and to determine the order of integration of the time series. Testing is performed on the logarithmically formed variables (LCPI, LUN and LGDP), i.e. the values of thetime series are transformed into the logarithm form, in order to eliminate heteroscedasticity, providing direct elasticities in the datasets. To test the stationarity of the time series of the variables considered, Augmented Dickey-Fuller (ADF) (Dickey \& Fuller, 1981), Philips-Perron (PP) (Phillips \& Perron, 1988), as well as the KPSS (Kwiatkowski et al., 1992) unit root test is used. Some authors have argued that some of the unit root tests provide biased results as they have no information about structural breaks occurringin the time series (Baum, 2004). In order to overcome this problem, in terms of the final decision on stationary series, Zivot and Andrews trended structural breaks unit root test is applied as well (1992).

To test the connection between economic growth and inflation in the presence of the unemployment, ARDL bounds testing approach is used, developed by (Pesaran et al., 2001). ARDL modeling is possible with the endogenous regressors (Alam \& Quazi, 2003). There is no need for precise identification of the order of the underlying series (Hsiao, 1997; Pesaran et al., 2001). This is of great importance in relation to the standard series cointegration analysis that requires the classification of the variables of the same order of integration. This approach has a number of advantages over the traditional cointegration techniques such as:

- The two step residual-based procedure for testing (Engle \& Granger, 1987);

- The system based reduced rank regression approach (Johansen, 1995);

- Variable addition approach (Park, 1990) and,

- The stochastic system approach (Stock \& Watson, 1988).

To test cointegration with all of these methods, the observed variables must be the order of integration I (1). In ARDL approach the relation between the variables is tested regardless of whether the variables are I (1), I (0) or mixed order of integration. This approach corresponds to a given sample, because the variables are of different order of integration, with the previously fulfilled condition that no variable is of the order of integration I (2). This approach is particularly suitable due to the fact that it is a small sample data as in this case, where you can get reliable results. ARDL model involves the formatting of the Unrestricted Error Correction Model (UECM). ARDL bounds testing approach can be written in the first step as follows:

$$
\begin{aligned}
& \Delta L G D P_{\mathrm{t}}=\alpha_{\mathrm{o}}+\alpha_{\mathrm{t}} T+\alpha_{G D P} L G D P_{t-1}+\alpha_{C P I} L C P I_{t-1}+\alpha_{U N} L U N_{t-1}+\sum_{i=1}^{p} \alpha_{i} \Delta L G D P_{t-i} \\
& +\sum_{j=0}^{q} \alpha_{j} \Delta L C P I_{t-j}+\sum_{t=0}^{m} \alpha_{l} \Delta L U N_{t-l}+\mu_{1} \\
& \Delta L C P I_{t}=\beta_{0}+\beta_{t} T+\beta_{G D P} L G D P_{t-1}+\beta_{C P I} L C P I_{t-1}+\beta_{U N} L U N_{t-1}+\sum_{j=1}^{p} \beta_{j} \Delta L C P I_{t-j} \\
& +\sum_{t=0}^{q} \beta_{l} \Delta L G D P_{t-l}+\sum_{n=0}^{m} \beta_{n} \Delta L U N_{t-n}+\mu_{i} \\
& \Delta L U N_{t}=\gamma_{\mathrm{o}}+\gamma_{t} T+\gamma_{G D P} L G D P_{t-1}+\gamma_{C P I} L C P I_{t-1}+\gamma_{U N} L U N_{t-1}+\sum_{i=1}^{p} \gamma_{i} \Delta L U N_{t-i} \\
& +\sum_{j=0}^{q} \gamma_{j} \Delta L C P I_{t-j}+\sum_{t=0}^{m} \gamma_{l} \Delta L G D P_{t-l}+\mu_{i}
\end{aligned}
$$

In the next step, the value of the $F$ statistics is calculated and compared, by rule, with tabulated critical bounds provided by (Pesaran et al., 2001). In this way, it is determined whether there is cointegration or not. The 
obtained value is compared to the upper critical bound and lower critical bound. Cointegration hypothesis implies the following situation, i.e. inequality to zero:

\section{Ha: $\alpha$ un $\neq \alpha$ cpi $\neq \alpha$ gdp $\neq 0$; \\ Ha: $\beta$ un $\neq \beta$ cpi $\neq \beta$ gdp $\neq 0$; \\ Ha: $\gamma$ un $\neq \gamma$ cpi $\neq \gamma g d p \neq 0$.}

If the computed value of the $F$ statistics exceeds the upper critical bound, then there exists cointegration. In case that there is evidence of cointegration between the variables in a logical sequence of events, we need to estimate both the long run and short run models. The hypothesis of no cointegration implies that the lower critical bound is above the calculated F statistics. In case the value of the F statistics falls inside lower and upper critical bounds, there are no clear enough conclusions on the cointegration. Error correction mechanism can be used for establishing cointegration (Kremers et al., 1992). In the end, it is necessary to test the stability of the long and short runs estimates by applying the tests of stability.

Since the focus of our attention is the relationship of the inflation and GDP, for further testing and verification of the relation between these two variables the causality test procedure is used. The most common operational definition of causality in econometrics is the definition of Granger (Granger, 1969): $x$ causes $y$ in Granger sense $(x \rightarrow y)$, if the current value of the variable $y$ can be predicted with greater accuracy based on the knowledge of the past values of the variable $x$, with other conditions unchanged (ceteris paribus). It is possible to conduct and form a VAR model based on Toda-Yamamoto procedure (Toda \& Yamamoto, 1995) relying on the results of the unit root tests. In this regard, it is necessary to specify the VAR model in levels, which in a general case for the two variables can be written as:

$$
\begin{aligned}
& Y_{t}=a_{0}+\sum_{i=1}^{k+d_{\max }} a_{1 i} Y_{t-i}+\sum_{i=1}^{k+d_{\max }} b_{1 i} X_{t-i}+e_{Y_{t}} \\
& X_{t}=c_{0}+\sum_{i=1}^{k+d_{\max }} c_{1 i} X_{t-i}+\sum_{j=1}^{k+d_{\max }} d_{1 i} Y_{t-i}+e_{X_{t}}
\end{aligned}
$$

Where $a_{0}$ and $c_{0}$ are the constants, $\mathrm{X}$ and $\mathrm{Y}$ are the variables, $a_{1 i}, b_{1 i}, c_{1 i}$ and $d_{1 i}$ are parameters of the model, $\mathrm{k}$ is the optimal lag order, $d_{\max }$ is the maximal order of integration and $e_{\mathrm{Yt}}$ and $e_{\mathrm{Xt}}$ are the random error with the distinction of white noise (Obradovic \& Grbic, 2015).

\section{Results and Discussion}

Results of ADF, PP and KPSS unit root tests shown in Table 1, indicate that the hypothesis that the time series LGDP and LUN are stationary in levels and in the first difference can be accepted. The third variable (LCPI), according to the results of the ADF and the PP tests, is not stationary in level, but is stationary in the first difference, which is not the case with the KPSS test by which this variable, is stationary too, in level and after the first difference. Relying on the results of the conducted unit root tests, we conclude that the studied time series are of different order of integration. According to the results of the ADF, PP and KPSS tests, we have two variables (LGDP and LUN) stationary in levels, and in the first difference I (0). The third variable (LCPI) is non-stationary in level, but stationary in the first difference i.e. has the order of integration I (1) based on the results of the ADF and PP tests.

The situation in which the possibility of a different order of integration is present, it is possible to do ARDL modelling and to develop a VAR model based on TodaYamamoto procedure (Toda and Yamamoto, 1995). The main assumption of the ARDL model is that the variables are not integrated at I (2), as the calculation of the F statistics will be invalid in decision making on existing the long run relation. The ARDL testing approach can be implemented if variables have order of integration I (1), I (0) or are mutually integrated. Therefore, the previous procedure applied three different unit root tests. The results obtained show that the maximum order of integration is at I (1). The results of Zivot and Andrews unit root test are shown in the table 2. In this way the robustness of stationarity properties is proved, which is further studied through this kind of a unit root test. Previous unit root tests is a necessity that must be implemented to avoid the possibility of certain variables being of the order I (2) or higher.

Table 1

\begin{tabular}{|c|c|c|c|c|c|c|}
\hline & \multicolumn{2}{|c|}{$\mathrm{ADF}$} & \multicolumn{2}{|c|}{ P-P } & \multicolumn{2}{|c|}{ KPSS } \\
\hline & Intercept & $\begin{array}{c}\text { Trend and } \\
\text { intercept }\end{array}$ & Intercept & $\begin{array}{l}\text { Trend and } \\
\text { intercept }\end{array}$ & Intercept & $\begin{array}{l}\text { Trend and } \\
\text { intercept }\end{array}$ \\
\hline \multicolumn{7}{|l|}{ Level } \\
\hline LGDP & $\begin{array}{l}-3.36 \\
(0.02)\end{array}$ & $\begin{array}{l}-3.97 \\
(0.02)\end{array}$ & $\begin{array}{c}-3.88 \\
(0.00)\end{array}$ & $\begin{array}{l}-3.32 \\
(0.08)\end{array}$ & $\begin{array}{c}0.33 \\
(0.74)\end{array}$ & $\begin{array}{c}0.08 \\
(0.22)\end{array}$ \\
\hline LUN & $\begin{array}{l}-6.15 \\
(0.00)\end{array}$ & $\begin{array}{l}-5.04 \\
(0.00)\end{array}$ & $\begin{array}{l}-5.82 \\
(0.00)\end{array}$ & $\begin{array}{l}-19.28 \\
(0.00)\end{array}$ & $\begin{array}{c}0.26 \\
(0.74)\end{array}$ & $\begin{array}{c}0.16 \\
(0.21)\end{array}$ \\
\hline LCPI & $\begin{array}{l}-2.45 \\
(0.14) \\
\end{array}$ & $\begin{array}{l}-3.19 \\
(0.11) \\
\end{array}$ & $\begin{array}{l}-1.21 \\
(0.66) \\
\end{array}$ & $\begin{array}{l}-2.11 \\
(0.52) \\
\end{array}$ & $\begin{array}{c}0.25 \\
(0.74) \\
\end{array}$ & $\begin{array}{c}0.11 \\
(0.22) \\
\end{array}$ \\
\hline \multicolumn{7}{|l|}{ First diff } \\
\hline $\mathrm{D}$ (LGDP) & $\begin{array}{l}-3.69 \\
(0.01)\end{array}$ & $\begin{array}{l}-3.55 \\
(0.05)\end{array}$ & $\begin{array}{l}-5.28 \\
(0.00)\end{array}$ & $\begin{array}{l}-5.51 \\
(0.00)\end{array}$ & $\begin{array}{c}0.24 \\
(0.74)\end{array}$ & $\begin{array}{c}0.09 \\
(0.22)\end{array}$ \\
\hline D(LUN) & $\begin{array}{l}-3.47 \\
(0.02) \\
\end{array}$ & $\begin{array}{l}-4.18 \\
(0.01) \\
\end{array}$ & $\begin{array}{l}-3.44 \\
(0.02) \\
\end{array}$ & $\begin{array}{l}-4.15 \\
(0.02) \\
\end{array}$ & $\begin{array}{c}0.55 \\
(0.74) \\
\end{array}$ & $\begin{array}{c}0.19 \\
(0.22) \\
\end{array}$ \\
\hline $\mathrm{D}(\mathrm{LCPI})$ & $\begin{array}{l}-4.63 \\
(0.00)\end{array}$ & $\begin{array}{l}-4.91 \\
(0.00)\end{array}$ & $\begin{array}{l}-3.99 \\
(0.00)\end{array}$ & $\begin{array}{l}-4.12 \\
(0.02)\end{array}$ & $\begin{array}{c}0.18 \\
(0.74)\end{array}$ & $\begin{array}{c}0.09 \\
(0.22)\end{array}$ \\
\hline
\end{tabular}

Unit Root Test Results

* The values in brackets are the corresponding probability (p-value) and asymptotic critical value at $1 \%$ level in the case of KPSS Unit Root Test

Source: Own calculation 
Zivot and Andrews unit Root Test

\begin{tabular}{|c|c|c|c|c|}
\hline Variable & \multicolumn{2}{|c|}{ At level } & \multicolumn{2}{|c|}{ At first difference } \\
\hline & t-stat. & Time break & t-stat. & Time break \\
\hline LGDP & -4.45 & 2009Q1 & -7.28 & 2009Q3 \\
\hline LUN & -4.99 & 2010Q3 & -7.16 & 2009Q2 \\
\hline LCPI & -2.21 & 2013Q3 & -6.13 & 2010Q3 \\
\hline
\end{tabular}

Source: Own calculation

Considering the fact that the results of the causality test, as well as of the F-statistics can be and are sensitive in relation to the structure of lags, the initial determination of the optimal lag length was of crucial importance to the accuracy and quality of the research (Feridun and Shahbaz, 2010). In determining the optimal lag order there are several criteria. In defining the optimal order of lags, the decision should be based primarily on the Akaike and Schwarz-Bayesian information criteria, as proposed by Pesaran et al. (2001).

Since we have found that the maximum order of integration $\left(\mathrm{d}_{\max }\right)$ is 1 , the next thing we determine is the optimal lag length $(\mathrm{k})$. In order to apply the ARDL model, selection of the appropriate lag length is necessary. To determine the optimal lag length most information criteria give unambiguous answer. In such a situation, in further analysis, the optimal number of lag order which should be equal to 2 is applied, when testing causality by Toda Yamamoto procedure, whereby also, we can not take the lag order more than 2 to apply the ARDL bounds testing. ARDL cointegration results are given in Table 3 . It shows the results of the calculated $F$ statistics when each variable is considered as dependent. The critical bounds generated by Pesaran et al. (2001) are not adequate for a small sample. They are generated via stochastic simulations for big data samples of 1000 observations and 40000 replications for the t-statistics. In our sample, we have 31 observations. We have used critical bounds provided by Turner (2006) which are more suitable for data like this. The critical bounds developed by Narayan (2005) are also suitable for small sample data (between 30 and 80 observations). After checking the evidence of the long run equilibrium, cointegration is established through the ARDL model where the GDP is a dependent variable. According to the test results, the calculated F-statistics $F_{\text {GDP }}$ $(\mathrm{GDP} / \mathrm{UN}, \mathrm{CPI})=13.69$ is higher than the upper bound critical values at 1,5 and $10 \%$ respectively. It is an important precondition for estimation of the long run and short run elasticities. Also, $\mathrm{F}_{\mathrm{CPI}}(\mathrm{CPI} / \mathrm{GDP}, \mathrm{UN})=6.05$ is higher than the upper bound critical level at the 5 percent. In these two cases, the null hypothesis of no cointegration is rejected.

But on the other hand, there is a problem with diagnostic tests, so we conclude that the third model can not give us reliable results. In the second model, where the unemployment is a dependent variable, we found no cointegraton relationship at 1,5 and $10 \%$ level.

The Results of ARDL Cointegration Test

Table 3

\section{Panel I: Bounds testing to cointegration}

\begin{tabular}{|c|c|c|c|}
\hline \multicolumn{4}{|c|}{ Panel I: Bounds testing to cointegration } \\
\hline Estimated models & $\mathrm{F}_{\mathrm{gdp}}(\mathrm{GDP} / \mathrm{UN}, \mathrm{CPI})$ & $\mathrm{F}_{\mathrm{un}}(\mathrm{UN} / \mathrm{GDP}, \mathrm{CPI})$ & $\mathrm{F}_{\mathrm{cpi}}(\mathrm{CPI} / \mathrm{GDP}, \mathrm{UN})$ \\
\hline Optimal lag structure & $(1,1,2)$ & $(1,1,1)$ & $(2,1,2)$ \\
\hline F statistics & 13.69 & 3.26 & 6.05 \\
\hline \multicolumn{4}{|c|}{$\begin{array}{c}\text { Significant level } \\
\text { Critical values }(T=31)\end{array}$} \\
\hline & Lower bounds & Upper bounds & \\
\hline $1 \%$ level & 6.8670 & 7.7748 & \\
\hline $5 \%$ level & 4.9136 & 5.7064 & \\
\hline $10 \%$ level & 4.0303 & 4.7585 & \\
\hline \multicolumn{4}{|c|}{ Panel II: Diagnostic tests } \\
\hline $\mathrm{R}^{2}$ & 0.77 & 0.53 & 0.63 \\
\hline Adjusted- $\mathrm{R}^{2}$ & 0.68 & 0.38 & 0.46 \\
\hline Breusch-Godfrey LM test & $0.73(0.50)$ & $0.15(0.86)$ & $2.54(0.11)$ \\
\hline Jarque-Bera normality test & $0.38(0.83)$ & $2.60(0.27)$ & $55.08(0.00)$ \\
\hline ARCH test for heteroscedasticity & $0.00(0.96)$ & $0.06(0.80)$ & $0.00(0.95)$ \\
\hline RAMSEY reset test & $0.19(0.67)$ & $0.09(0.77)$ & $0.25(0.62)$ \\
\hline
\end{tabular}

Source: Own calculation

Within the cointegration test results, a number of standard diagnostic tests are done. LM test, JB test, ARCH test and Ramsey RESET test are post-estimation diagnostic tests for the robustness of the model. In the first model where GDP is a dependent variable, Jarque-Bera normality test reveals that the estimated residuals are normally distributed. ARCH LM test reports that there is no heteroskedasticity problem. According to Breusch-Godfrey LM test, residuals are not serially correlated. Ramsey RESET test confirms that the functional form of the model is well specified. The normality test in the third model rejects null hypothesis which considers that the residuals are normally distributed. In other words, that means that the standard statistics are not valid for the third model (i.e. F-stat. t-stat. and R-squares). 
Sasa Obradovic, Srdan Sapic, Srđan Furtula, Nemanja Lojanica. Linkages between Inflation and Economic Growth in ...

Table 4

Long and Short Run Results - Dependent Variable LGDP

\begin{tabular}{|c|c|c|}
\hline \multicolumn{3}{|c|}{ Long run analysis } \\
\hline Variable & Coefficient & t-statistic \\
\hline $\mathrm{c}$ & 10.88 & 10.75 \\
\hline lun & 0.40 & 2.64 \\
\hline lcpi & 0.00 & 0.07 \\
\hline \multicolumn{3}{|c|}{ Short run analysis } \\
\hline $\mathrm{c}$ & -0.00 & -0.09 \\
\hline$\Delta$ lun & 0.07 & 0.5769 \\
\hline$\Delta \mathrm{lcpi}$ & 0.02 & 2.38 \\
\hline $\operatorname{ECM}(-1)$ & -0.64 & -1.93 \\
\hline \multicolumn{3}{|c|}{ Short run diagnostic test } \\
\hline $\mathrm{R}^{2}$ & 0.47 & \\
\hline Adjusted- $\mathrm{R}^{2}$ & 0.33 & \\
\hline \multirow[t]{2}{*}{ F-statistics } & 3.41 & \\
\hline & Statistic & Prob. value \\
\hline Breusch-Godfrey LM test & 1.62 & 0.23 \\
\hline Jarque-Bera normality test & 1.51 & 0.47 \\
\hline ARCH test for heteroscedasticity & 0.36 & 0.55 \\
\hline RAMSEY reset test & 0.83 & 0.37 \\
\hline
\end{tabular}

Source: Own calculation

The next step shows and provides the short run parameters by estimating the ECM associated with the long run parameters. Through the transformation that covers the short run adjustments with the long run equilibrium, we derived error correction mechanism from ARDL. It is calculated without losing the long run estimates (Pesaran and Shin, 1999). This is specified:

$$
\Delta L G D P_{\mathrm{t}}=\alpha_{0}+\alpha_{\mathrm{t}} T+\sum_{i=1}^{p} \alpha_{i} \Delta L G D P_{t-i}+\sum_{j=0}^{q} \alpha_{j} \Delta L C P I_{t-j}+\sum_{l=0}^{m} \alpha_{l} \Delta L U N_{t-l}+\mu_{\mathrm{i}}+e c m_{t-1}
$$

In the long run, there is a connection among inflation, unemployment and GDP, in the case when the GDP is a dependent variable (Table 4). Our empirical results indicate that unidirectional short run causality is found between inflation and economic growth in the short run, and between unemployment and economic growth in the long run. ECM is between 0 and -1 and has a statistical significance. In other words, it means that the speed of adjustment is $64.4 \%$ compared to the equilibrium path. This implies that any future deviation from the equlibrium level of GDP during the current period will be reduced by $64.4 \%$ in the next period of time. The corresponding coefficients are the confirmation of the previously established cointegration relation. In the long run, the growth of unemployment has a stimulating effect on growth, which is explained by structural changes within the economy itself, where by reducing the excess staff makes the increase in efficiency, while on the other hand, inflation has no effect on growth. In the short run, there is a short run connection between inflation and economic growth, that is, changes in inflation can have a stimulating influence on the changes in GDP, if there is such a line of causality. On the other hand, it has not been proved that changes in unemployment affect the movement of GDP. Based on the results, it can be noted that a $1 \%$ increase in inflation is linked with an increase in GDP by $0.02 \%$.

The stability of short and long run coefficients is checked through the Cumulative Sum of Recursive Residuals and the Cumulative Sum of Squares of Recursive Residuals tests proposed by Brown et al. (1975). According tothe test results for the given regression, we conclude that the null hypothesis can not be rejected. The plots stay within the critical bounds of a $5 \%$ level of significance (Figure 2 and Figure 3). Model parameters are stable and efficient.

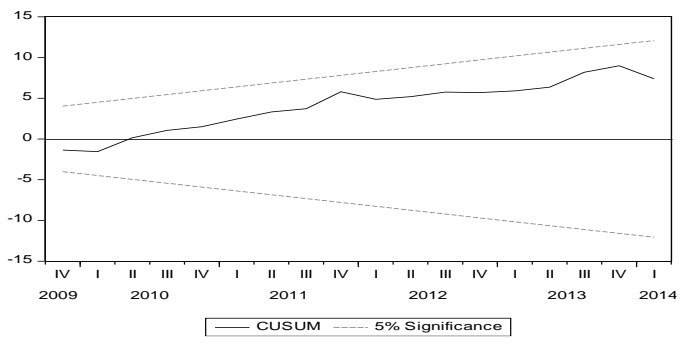

Figure 2. Plot of Cumulative Sum of Recursive Residuals $\operatorname{ARDL}(1,1,2) \mathrm{GDP}$ as a Dependent Variable

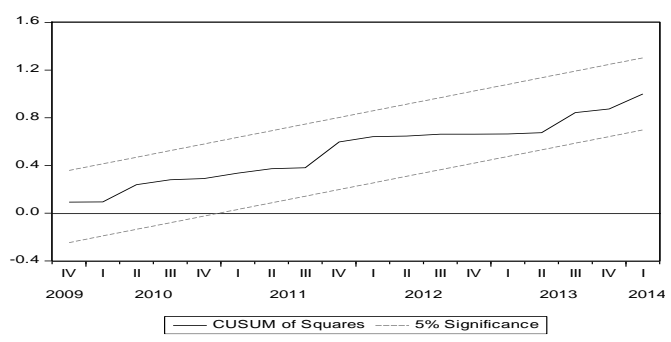

Figure 3. The Cumulative Sum of Squares of Recursive Residuals

After setting the short and long run effects of inflation and unemployment on GDP, it is necessary to explore the direction of casual relation between the variables of interest. The existence of a long run relationship between the variables is a necessary, but not a sufficient condition in terms of causality hypothesis (Morley, 2006). 
This paper explores the causality through bivariate modeling, as this procedure is adequate, even when the order of integration is mixed. There is no need for pretesting of cointegration of the series. However, for the model to be valid, the condition $\mathrm{k}>\mathrm{d}_{\max }$ must be fulfilled. To obtain a valid chi square statistics that is asymptotically normally distributed, we used Mwald test for the parameter restrictions on the VAR (k) from augmented VAR (Zapata and Rambaldi, 1997). Granger noncausality is derived from dynamic system of augmented VAR $\left(k+d_{\text {max }}\right)$. The model is estimated on Seemingly Unrelated Regression.

Finally, we conduct the test of causality. Specifically based on the preset equation, the hypothesis " $\mathrm{X}$ does not cause $\mathrm{Y}$ in terms of Granger" is tested i.e., we test the hypothesis "Y does not cause $\mathrm{X}$ in terms of Granger". The existence of causality is confirmed by the rejection of the null hypothesis in the case when the value of the test is statistically significant. The conducted empirical research in a number of countries around the world has shown that the causal link between inflation and economic growth can be unidirectional or bidirectional. Test results of the TodaYamamoto model are shown in Table 5. The null hypothesis that the inflation does not cause GDP is rejected, which means that there is a causal relation in Granger terms from the direction of inflation to the economic growth. Otherwise, the results indicate that there is no unidirectional causal relation that goes from the direction of economic growth to inflation based on the results of the testing.

Results of the Granger Non-Causality Test

Table 5

\begin{tabular}{|c|c|c|c|}
\hline Null Hypothesis & Chi-square & df & Probability \\
\hline Inflation does not Granger cause GDP & 6.12 & 2 & 0.05 \\
\hline GDP does not Granger cause Inflation & 0.45 & 2 & 0.80 \\
\hline
\end{tabular}

Source: Own calculation

Results of the analysis indicate the existence of the unidirectional causality. The analysis shows that in the case of Serbia, there is no certainty that the lower inflation is the driver of the economic growth or vice versa, that higher inflation affects the reduction in growth performance. However, it should be noted that the causal link depends on a range of other factors that are not covered by this research. Our conducted empirical research has confirmed that there is causality from inflation to economic growth, while causality from growth to inflation has not been found.

Impulse response function (IRF) examines the impact of shocks on the observed macroeconomic series. Since the shock in a variable affects not only the variable itself, but also other endogenous variables through a dynamic structure of the VAR model, the IRF shows the effects of a simultaneous positive innovation shock in one variable on the current and future value of endogenous indicators. IRF, in a way, is a result of the conceptual experiment. This function is designed to solve the conceptual problems: history, shocks and dependence of composition. With this function, there are two types of shocks: the permanent (permanent movement from the line of zero) and transient (occasional movement from the zero line, and then return to the state of equilibrium). Relating to the data from the Figure 4, it is evident that after twenty periods (five years) effects largely subside. More specifically, only shocks in inflation have effects on transitory changes of the economic growth. Such a result is not a surprise, since it is just in the short run that the short run causality, from the direction of inflation to economic growth, is confirmed.

Response to Generalized One S.D. Innovations \pm 2 S.E.
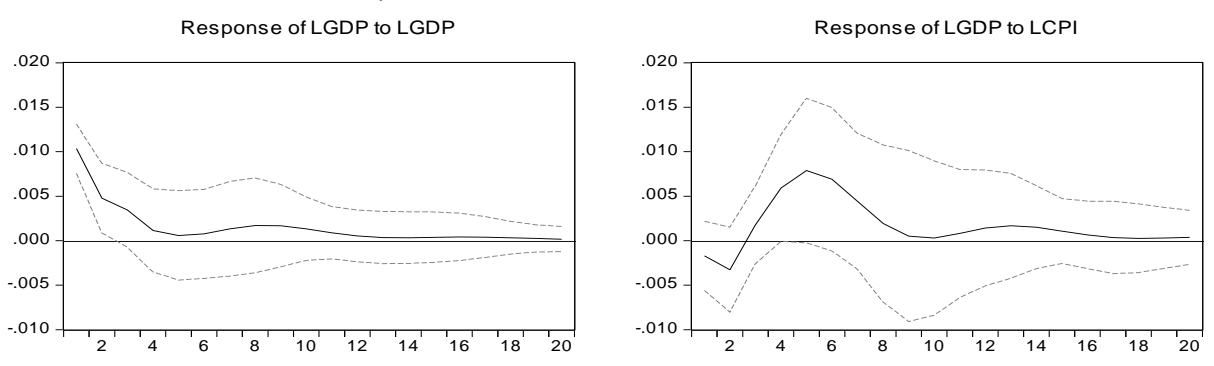

Response of LCPI to LGDP
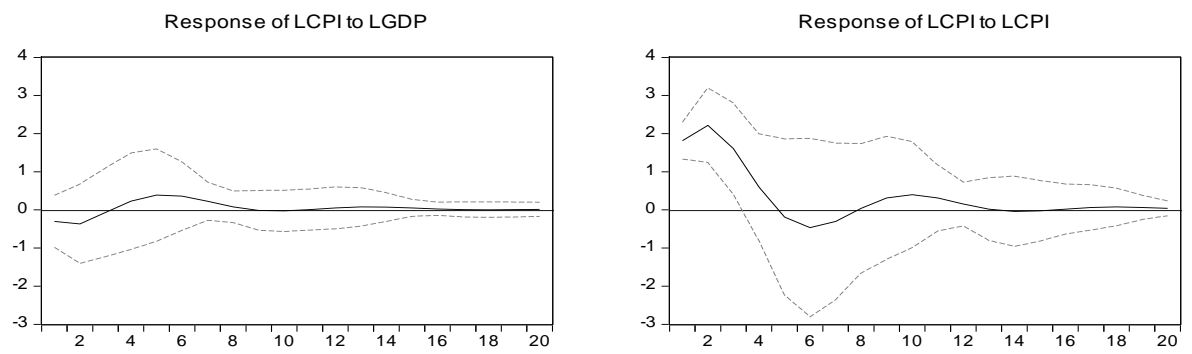

Figure 4. Impulse Response Function 


\section{Conclusion and Future Directions}

In this paper, we have examined linkages between inflation and economic growth in the case of Serbia (based on the given sample and the time period). To achieve the objective of this study, the interdependence between the two observed variables was investigated by using the concept of the causality test. The direction of causality between the series was tested by applying Toda-Yamamoto approach. Inflation Granger caused economic growth.

These results carry the appropriate macroeconomic implications, too. First, the fact that the changes in the rate of inflation are linked with changes in economic growth should be taken into consideration in the economic policy implementation. Secondly, the economy of the Republic of Serbia has achieved low, and even negative economic growth rates in recent years. On the other hand, Serbia has hada high rate of inflation for many years. The previous period was characterized by an extremely low level of confidence in the national currency. Therefore it is necessary to pay attention to the adequate control of this phenomenon in the future.

On the basis of everything indicated in the paper, it has been shown that the growth in the economy of Serbia is linked with the inflation rate increase. Our results have found that the short run relationship exists between the inflation and economic growth on the observed sample. In other words, expansive monetary policy could increase aggregate demand, employment and economic growth in the short run, nonetheless the effect of such measures would be ultimately counterproductive from the aspect of the long-term interests. Considering the fact that such an economic growth is followed by the price increase it can cause hyperinflationary effects. The bearers of the monetary policy in the Republic of Serbia face a permanent and a very sensitive task of the improvement of economic activity in order to reach the adequate growth rate that would be consistent to the maintainance of the stable and low inflation rate in the long run.

Previously obtained results are in accordance with the hypothesis of the paper that, ultimately, stable and sustainable economic growth requires price stability. The benefits of inflation increase in terms of its reflection on economic growth rate are negligible in the short run compared to possible negative effects. This certainly does not meant hat economic growth is only interpreted on the basis of its relationship with inflation, as it may be influenced by many other factors, which are not included in this analysis. According to the fact that Serbia has introduced an inflationary targeting regime, and in terms of any further researches, it is advisible to investigate the effects of money supply and interest rate on these two variables, that is, the activity of the transmission mechanism of monetary processes in the Republic of Serbia, in the context of designing the appropriate monetary policy.

\section{Acknowledgement}

This research was supported by Serbian Ministry of Education, Science and Technological Development with project no. 179015.

\section{References}

Alam, M. I., \& Quazi, R. M. (2003). Determinants of capital flight: An econometric case study of Bangladesh. International Review of Applied Economics, 17(1), 85-103. doi:10.1080/713673164

Andres, J., \& Hernando, I. (1997). Does inflation harm economic growth? Evidence from the OECD. NBER Working Paper No. 062, Cambridge MA: National Bureau of Economic Research. doi:10.3386/w6062

Baharumshah, A. Z., Slesman, L., \& Wohar, M. E. (2016). Inflation, inflation uncertainty, and economic growth in emerging and developing countries: Panel data evidence. Economic Systems, 40(4), $638-657$. doi: $10.1016 /$ j.ecosys.2016.02.009

Balcilar, M., Gupta, R., \& Jooste, C. (2017). The growth-inflation nexus for the U. S. from 1801 to 2013: A semiparametric approach. Journal of Applied Economics, 20(1), 105-120. doi:10.1016/S1514-0326(17)30005-3

Barro, R. (1995). Inflation and economic growth. NBER Working Paper No.5326, Cambridge MA: National Bureau of Economic Research. doi:10.3386/w5326

Baum C. F. (2004). A review of Stata 8.1 and its time series capabilities. International Journal of Forecasting, 20(1), 151161. doi:10.1016/j.ijforecast.2003.11.007

Brown, R. L., Durbin, J., \& Evans, J. M. (1975). Techniques for Testing the Constancy of Regression Relations Over Time. Journal of the Royal Statistical Society, Series B, 37, 149-163.

Caporale, G. M., \& Skare, M. (2014). Short- and long-run linkages between employment growth, inflation and output growth: Evidence from a large panel. Technological and Economic Development of Economy, 20(3), 554-575. doi:10.3846/20294913.2014.966349

Dickey, D. A., \& Fuller, W. A. (1981). Likelihood ratio statistics for autoregressive time series with a unit root. Econometrica, 49(4), 1057-1072. doi:10.2307/1912517

Engle, R. F., \& Granger, C. W. J. (1987). Co-integration and Error-correction: Representation, Estimation and Testing. Econometrica, 55(2), 251-276. doi:10.2307/1913236 
Erbaykal, E., \& Okuyan, A. (2008). Does inflation depress economic growth? Evidence from Turkey. International Research Journal of Finance and Economics, 13(17), 40-48.

Faria, R. J., \& Carneiro, F. G. (2001). Does high inflation affect growth in the long and short-run? Journal of Applied Economics, 4(1), 89-105.

Feridun, M., \& Shahbaz, M. (2010). Fighting Terrorism: Are Military Measures Effective? Empirical Evidence from Turkey. Defence and Peace Economics, 21(2), 193-205. doi:10.1080/10242690903568884

Fischer, S. (1977). Long-term Contracts, Rational Expectations, and the Optimal Money Supply Rule. Journal of Political Economy, 85(1), 191-205. doi:10.1086/260551

Friedman, M. (1983). A Program for Monetary Stability. Fordham University Press: New York.

Granger, C. W. J. (1969). Investigating causal relation by econometric models and cross-spectral method. Econometrica, 37(3), 424-438. doi:10.2307/1912791

Hsiao, C. (1997). Cointegration and dynamic simultaneous equation model. Econometrica, 65(3), 647-670. doi: $10.2307 / 2171757$

Jayathileke, P. M. B., \& Rathnayake, R. M. K. T. (2013). Testing the link between inflation and economic growth: Evidence from Asia. Modern Economy, 4(2), 87-92. doi:10.4236/me.2013.42011

Johansen, S. (1995). Likelihood-Based Inference in Cointegrated Vector Autoregressive Models. Oxford University Press: New York. doi:10.1093/0198774508.001.0001

Koulakiotis, A., Lyroudi, K., \& Papasyriopoulous, N. (2012). Inflation, GDP and causality for European countries. International Advances in Economic Research, 18(1), 53-62. doi:10.1007/s11294-011-9340-1

Kremers, J., Ericsson, N., \& Dolado, J. (1992). The Power of Cointegration Tests. Oxford Bulletin of Economics and Statistics, 54(3), 325-348. doi:10.1111/j.1468-0084.1992.tb00005.x

Kwiatkowski, D., Philips, P., Schmidt, P., \& Schin, Y. (1992). Testing the null hypothesis of stationarity against the alternative of a unit root: How sure are we that economic time series have a unit root? Journal of Econometrics, 54(1/3), 159-178. doi:10.1016/0304-4076(92)90104-y

Mallik, G., \& Chowdury, A. (2001). Inflation and economic growth : Evidence from four south Asian countries. AsiaPacific Development Journal, 8(1), 123-135.

Morley, B. (2006). Causality between Economic Growth and Immigration: An ARDL Bounds Testing Approach. Economics Letters, 90(1), 72-76. doi:10.1016/j.econlet.2005.07.008

Narayan, P. K. (2005). The saving and investment nexus for China: evidence from cointegration tests. Applied Economics, 37(17), 1979-1990. doi:10.1080/00036840500278103

National Bank of Serbia (2015). Data for the real sector, Available from internet: http://www.nbs.rs/internet/ latinica/80/index.html

Obradovic, S., \& Grbic, M. (2015). Causality Relationship between Financial Intermediation by Banks and Economic Growth: Evidence from Serbia. Prague Economic Papers, 24(1), 60-72. doi:10.18267/j.pep.500

Ormerod P., Rosewell B., \& Phelps P. (2013). Inflation/unemployment regimes and the instability of the Phillips curve. Applied Economics, 45(12), 1519-1531. doi:10.1080/00036846.2011.628299

Park, J. Y. (1990). Testing for unit roots by variable addition. In Advances in Econometrics: Cointegration, Spurious Regressions and Unit Roots. Fomby TB, Rhodes RF (eds). JAI Press: Greenwich, CT.

Pesaran, M. H., \& Shin, Y. (1999). An autoregressive distributed lag modelling approach to cointegration analysis. In S. Strom (Ed.), Econometrics and Economic Theory in the 20th Century: The Ragnar Frisch Centennial Symposium, Cambridge University Press: Cambridge. doi:10.1017/ccol521633230.011

Pesaran, M. H., Shin, Y., \& Smith, R., J. (2001). Bounds testing approaches to the analysis of level relationships. Journal of Applied Econometrics, 16(3), 289-326. doi:10.1002/jae.616

Phillips, A. W. (1962). Employment, Inflation and Growth. Economica, 29(113), 1-16. doi:10.2307/2601516

Phillips, P. C., \& Perron, P. (1988). Testing for a Unit Root in Time Series Regressions. Biometrika, 75(2), 335-346. doi:10.1093/biomet/75.2.335

Pindyck, R., \& Solimano, A. (1993). Economic instability and aggregate investment. NBER Working Paper No. 4380, Cambridge, MA: National Bureau of Economic Research, 1-53. doi:10.3386/w4380

Republic Institute for Statistics (2015). Data on employment and earnings. Available from internet: webrzs.stat.gov.rs/WebSite/public/ReportView.aspx

Simhon, A., \& Bar-Shira Z. (2001). Inflation Rate Variability and the Phillips Curve. Review of International Economics, 9(2), 329-335. doi:10.1111/1467-9396.00282

Stock, J., \& Watson, M.W. (1988). Testing for common trends. Journal of the American Statistical Association, 83, 10971107. doi:10.1080/01621459.1988.10478707 
Sasa Obradovic, Srdan Sapic, Srđan Furtula, Nemanja Lojanica. Linkages between Inflation and Economic Growth in ...

Toda, H., \& Yamamoto, T. (1995). Statistical inference in vector autoregressions with possibly integrated processes. Journal of Econometrics, 66(1/2), 225-250. doi:10.1016/0304-4076(94)01616-8

Turner, P. (2006). Response surfaces for an F-test for cointegration. Applied economics letters, $13(8), 479-482$. doi:10.1080/13504850500401726

Valdovinos, F. (2003). Inflation and economic growth in the long run. Economic Letters, 80(2), $167-173$. doi:10.1016/s0165-1765(03)00085-5

Zapata, H. O., \& Rambaldi, A. N. (1997). Monte Carlo evidence on cointegration and causation. Oxford Bulletin of Economics and Statistics, 59(2), 285-298. doi:10.1111/1468-0084.00065

Zivot, E., \& Andrews, D. (1992). Further evidence of great crash, the oil price shock and unit root hypothesis. Journal of Business and Economic Statistics, 10(3), 251-270. doi:10.1080/07350015.1992.10509904

The article has been reviewed.

Received in January, 2016; accepted in October, 2017. 